Jurnal PG-PAUD Trunojoyo : Jurnal Pendidikan dan Pembelajaran Anak Usia Dini, Volume 7, Nomor 2, Oktober 2020 hal 62-68, ISSN : 2528-3553 (online), ISSN: 2407-4454 (print)

\title{
PENGEMBANGAN MEDIA BUKU DONGENG FABEL UNTUK MENGENALKAN KEAKSARAAN ANAK USIA 5-6 TAHUN DI WONOREJO GLAGAH
}

\author{
Lailatul Izzah ${ }^{1}$ \\ Dwi Nurhayati Adhani ${ }^{2}$ \\ Siti Fadjryana Fitroh ${ }^{3}$ \\ 1,2,3PG-PAUD, Universitas Trunojoyo Madura \\ Email: lailatulizzah1995@gmail.com,dwinadhani@gmail.com,fadjryana.fitroh@trunojoyo.ac.id \\ Received (Juni), Accepted (September), Published (Oktober)
}

\begin{abstract}
The Development Book Fable To Introduce Literacy Children Aged 5-6 Years In Wonorejo Glagah. Research aims to create and develop fairy-tales learning media Fable Elang and Kelinci in the Wonorejo District Glagah Lamongan Regency that can be used to introduce the ability of literacy children aged 5-6 years to assist teachers in delivering lesson materials. This learning media is made by drawing contents in a fairy tale and combining images and text with Microsoft Word and then printed in book form, in addition to knowing the feasibility of this learning medium. This research was conducted in the district Wonorejo Glagah Lamongan Regency, is a development research (Reseach and Development). The research object is a fairytale learning medium fable eagles and rabbits. Stages of research include (1) analysis (analysis), (2) Design (Design), (3) Develpment (development), (4) Implementation (Implementation), (5) evaluation. The data collection techniques used are using questionnaires and a questionnaire analyzed quantitatively and qualitative. The subject of research is 5-6 years of age in the Wonorejo Glagah Lamongan. The results of this study are the media of the fairytale learning Fable Elang and Kelinci, with a percentage of eligibility (1) The assessment of the media experts gained a percentage of $66.6 \%$ with a fairly decent category, (2) The assessment of the materials and language experts obtained a percentage of $84.5 \%$ with decent category, (3) Assessment of the individual field response poll test received a percentage of $85.5 \%$ with decent category, (4) Assessment of small field response poll test gained a percentage of $92.5 \%$ with very decent category. Conclusion: Learning Media fairy tale fable Elang and rabbit worthy of use in the learning process introduction of literacy skills aged 5-6 years in the district Wonorejo Glagah Lamongan Regency.
\end{abstract}

Keywords: Learning Media, fairy tale fable, early childhood literacy.

Abstrak: Pengembangan Media Buku Dongeng Fabel Untuk Mengenalkan Keaksaraan Anak Usia 5-6 Tahun Di Wonorejo Glagah. Penelitian ini bertujuan untuk membuat dan mengembangkan media pembelajaran dongeng fabel Elang dan Kelinci di Wonorejo Kecamatan Glagah Kabupaten Lamongan yang dapat digunakan untuk mengenalkan kemampuan keaksaraan anak usia 5-6 tahun sehingga membantu pengajar dalam menyampaikan materi pelajaran. Media pembelajaran ini dibuat dengan menggambar isi dalam dongeng dan menggabungkan gambar dan teks dengan microsoft word kemudian dicetak dalam bentuk buku, selain itu juga untuk mengetahui kelayakan media pembelajaran ini. Penelitian ini dilaksanakan di Wonorejo Kecamatan Glagah Kabupaten Lamongan, merupakan penelitian pengembangan (Reseach and Development). Obyek penelitian adalah media pembelajaran dongeng fabel Elang dan Kelinci. Tahap penelitian meliputi (1) Analysis (Analisis), (2) Design (Desain), (3) Develpment (Pengembangan), (4) Implementation (Implementasi), (5) Evaluation (Evaluasi). Teknik pengumpulan data yang digunakan adalah menggunakan angket dan kuesioner yang dianalisis secara kuantitatif dan kualitatif. Subyek penelitian adalah anak usia 5-6 tahun di Wonorejo Glagah Lamongan. Hasil penelitian ini adalah media pembelajaran dongeng fabel Elang dan Kelinci, dengan persentase kelayakan (1) Penilaian dari ahli media memperoleh presentase 66,6\% dengan kategori cukup layak, (2) Penilaian dari ahli materi dan bahasa memperoleh presentase $84,5 \%$ dengan kategori layak, (3) Penilaian dari uji angket respons lapangan perseorangan memperoleh presentase $85,5 \%$ dengan kategori layak, (4) Penilaian dari uji angket respons lapangan kelompok kecil memperoleh presentase 92,5\% dengan kategori sangat layak. Kesimpulan: Media Pembelajaran Dongeng Fabel Elang dan Kelinci Layak digunakan dalam proses pembelajaran pengenalan kemampuan keaksaraan anak usia 5-6 tahun di Wonorejo Kecamatan Glagah Kabupaten Lamongan.

Kata kunci: media pembelajaran, dongeng fabel, keaksaraan anak usia dini.

Copyright (c) 2020 Lailatul Izzah, Dwi Nurhayati Adhani, Siti Fadjryana Fitroh 
Jurnal PG-PAUD Trunojoyo : Jurnal Pendidikan dan Pembelajaran Anak Usia Dini, Volume 7, Nomor 2, Oktober 2020 hal 62-68, ISSN : 2528-3553 (online), ISSN: 2407-4454 (print)

\section{PENDAHULUAN}

Anak usia dini menurut Diana merupakan anak dengan usia lahir hingga usia 6 tahun, serta pada masa ini anak diberikan rangsangan pendidikan untuk membantu pertumbuhan dan pekembangan anak (Mutiah, 2010). Pada usia ini orang dewasa yaitu orang tua, guru, dan orang di sekitarnya memiliki peran penting dalam rangsangan pada anak. Pemberian rangsangan yang tepat pada anak akan membantu anak dalam menyiapkan diri untuk memasukin fase pendidikan yang selanjutnya. Sejalan dengan pendapat Diana, menurut NAEYC (National Association For Then Education Of Young Children) dalam Aisyah yang menyatakan bahwa "anak usia dini adalah anak yang berada pada rentang usia 0-8 tahun, yang mencakup dalam program pendidikan di taman penitipan anak, penitipan anak keluarga (family child care home), pendidikan prasekolah baik swasta maupun negeri, TK, dan SD" (Aisyah, 2012). Berdasarkan beberapa pendapat yang mengenai pengertian anak usia dini yang telah dikemukakan di atas, dapat disimpulkan bahwa anak usia dini adalah anak yang sejak lahir hingga berusia 6 tahun atau yang sering disebut sebagai "golden age" (usia emas), yang memiliki proses pertumbuhan dan perkembangan yang bersifat unik.

Karakteristik anak usia dini diantaranya adalah unik, egosentris, aktif dan energik, rasa ingin tahu yang kuat dan antusias terhadap banyak hal, eksploratif, spontan, senang dan kaya fantasi, masih mudah frustasi, masih kurang pertimbangan dalam melakukan sesuatu, daya perhatian yang pendek, bergairah untuk belajar dan banyak belajar dari pengalaman, semakin menunjukkan minat terhadap teman, yaitu anak mulai menunjukkan untuk bekerja (Fadlillah, 2012).

Anak usia dini terdapat 7 aspek dalam pertumbuhan dan perkembangan secara bertahap. Menurut Fadlillah terdapat 7 aspek dasar perkembangan anak usia dini, yaitu perkembangan fisik motorik, perkembangan kognitif, perkembangan moral, perkembangan emosi, perkembangan bahasa, perkembangan sosial, dan perkembangan imajinasi (Fadlillah, 2012). Perkembangan bahasa adalah suatu perkembangan kemampuan berkomunikasi dengan orang lain dengan pikiran dan perasaan yang dinyatakan dalam bentuk lisan, tertulis, isyarat, atau gerak dengan menggunakan kata-kata, simbol, lambang dan gambar.

Proses pelaksanaan pembelajaran dikatakan berhasil apabila anak dapat menerima pesan yang guru sampaikan dan anak dapat melakukan perintah dari guru dengan baik. Terdapat banyak jenis metode pembelajaran PAUD yang dapat dilakukan guru untuk memudahkan proses pelaksanaan pembelajaran antara lain dengan metode bermain, metode pemberian tugas, metode demontrasi, metode tanya jawab, metode eksperimen, metode karya wisata, dan metode bercerita atau mendongeng. Salah satu cara dalam mengenalkan keaksaraan anak dengan mendongeng, diantaranya dengan menggunakan media pembelajaran.

Oleh sebab itu, media sangat diperlukan dalam proses pembelajaran, karena media mampu memberikan variasi dalam pembelajaran, memberi kesempatan pada anak untuk mengulang pelajaran yang diberikan, memperlancar pelaksanaan kegiatan pembelajaran dan memudahkan tugas guru. Media juga dapat digunakan untuk meningkatkan perkembangan pada anak usia dini. Adapun pengertian media yang menyangkut pembelajaran metode bercerita atau mendongeng menggunakan media visual.

Media berasal dari bahasa latin yaitu medium, yang berarti perantara, antara, atau pengantar. Media didefinisikan sebagai pengantar pesan dari pengirim pesan ke penerima pesan. Pemanfaatan media dalam kegiatan pembelajaran anak usia dini pada umumnya bertujuan untuk menyampaikan bagian tertentu dari kegiatan pembelajaran, 
Jurnal PG-PAUD Trunojoyo : Jurnal Pendidikan dan Pembelajaran Anak Usia Dini, Volume 7, Nomor 2, Oktober 2020 hal 62-68, ISSN : 2528-3553 (online), ISSN: 2407-4454 (print)

memberikan penguatan maupun motivasi. Beberapa peranan penting media dalam kegiatan pembelajaran adalah memperjelas penyajian pesan dan mengurangi verbalitas (Eliyawati, 2005).

Berdasarkan cara penyampaian dan penerimaannya, media terbagi menjadi tiga yaitu media audio, media visual dan media audio visual. Media visual adalah media yang dapat dilihat dan digunakan untuk membantu menyampaikan isi dari tema pendidikan yang sedang dipelajari (Muhtar, 2014). Contoh media visual yang dapat digunakan untuk mengenalkan kemampuan keaksaraan anak usia dini yaitu buku dongeng fabel. Media dongeng fabel yaitu adalah cerita tentang kehidupan binatang, cerita binatang di dalam fabel dapat berpikir, bereaksi, dan berbicara seperti manusia. Cerita fabel tidak hanya menghibur tetapi bersifat mendidik, banyak nilai moral yang dapat dijadikan sebagai pelajaran. Dengan adanya gambar pada dongeng fabel, maka dapat digunakan sebagai daya tarik agar anak bersedia mendengarkan dongeng fabel dan belajar mengenal kemampuan keaksaraan dari kata yang ada dalam dongeng fabel tersebut.

Berdasarkan pada Peraturan Menteri Pendidikan dan Kebudayaan Republik Indonesia Nomor 137 Tahun 2014 Tentang Standar Nasional PAUD Bab 4 pasal 10 ayat 5 bahwa perkembangan bahasa meliputi: Bahasa sebagaimana dimaksud pada ayat (1) terdiri atas: a. memahami bahasa reseptif, mencakup kemampuan memahami cerita, perintah, aturan, menyenangi dan menghargai bacaan; b. mengekspresikan bahasa, mencakup kemampuan bertanya, menjawab pertanyaan, berkomunikasi secara lisan, menceritakan kembali yang diketahui, belajar bahasa pragmatik, mengekspresikan perasaan, ide, dan keinginan dalam bentuk coretan; dan c. keaksaraan, mencakup pemahaman terhadap hubungan bentuk dan bunyi huruf, meniru bentuk huruf, serta memahami kata dalam cerita. Lingkup perkembangan bahasa anak mencakup aspek keaksaraan untuk anak usia 4 sampai 6 tahun. Dalam aspek keaksaraan anak diajarkan mengenal simbolsimbol, mengelompokkan bunyi dan huruf, menulis dan membaca nama sendiri, serta memahami arti dalam sebuah cerita.

Pendidikan keaksaraan harus dimunculkan sejak anak usia dini, dilingkungan yang bermutu sesuai dengan perkembangan, keaksaraan itu tertanam sepanjang hari dan ada pada pengalaman bermain anak. Anak usia dini akan mengembangkan pengetahuan keaksaraan melalui intensitas interaksi dengan buku, bahasa, pengalaman motorik kasar dan halus. Perkembangan keaksaraan diperoleh melalui pengalaman yang menyenangkan yang disediakan untuk anak usia dini selama bermain (Yusro, 2013).

Berdasarkan fakta-fakta yang sudah ada, banyak sekolah-sekolah yang hanya menggunakan metode demonstrasi. Di sekolah, guru jarang menggunakan metode bercerita karena dianggap membosankan untuk anak-anak, padahal ketika menerapkan metode bercerita dengan baik dan benar anak akan mendapatkan stimulasi yang tepat untuk perkembangan bahasanya. Untuk mengajarkan aspek keaksaraan guru hanya sering menggunakan teknik membaca tanpa ada media dan metode yang menyenangkan bagi anak, sehingga anak kurang memahami simbol-simbol yang ada.

Metode bercerita atau mendongeng akan lebih menarik dan menyenangkan dengan menggunakan media belajar, salah satu media yang dapat digunakan yakni buku dongeng fabel. Media buku dongeng fabel merupakan cerita yang ditulis dengan gaya bahasa ringan yang dilengkapi gambar kemudian menjadi satu kesatuan. Tema dalam cerita tidak jarang berkaitan dengan pribadi/pengalaman pribadi sehingga pembaca mudah mengidentifikasikan dirinya melalui perasaan serta tindakan dirinya melalui perwatakan tokoh-tokoh utamanya. 
Jurnal PG-PAUD Trunojoyo : Jurnal Pendidikan dan Pembelajaran Anak Usia Dini, Volume 7, Nomor 2, Oktober 2020 hal 62-68, ISSN : 2528-3553 (online), ISSN: 2407-4454 (print)

Penggunaan dongeng fabel diharapkan dapat mengenalkan kemampuan keaksaraan pada anak usia dini khususnya pada anak usia 5-6 tahun di Desa Wonorejo.

Berdasarkan hasil observasi yang dilakukan peneliti pada tanggal 20 sampai dengan 26 Januari 2020 di Desa Wonorejo diketahui beberapa anak belum menguasai lingkup perkembangan bahasa mengenai keaksaraan. Hal ini ditunjukkan seperti anak masih belum bisa menulis namanya sendiri, anak juga belum bisa membaca namanya sendiri dan yang paling terlihat adalah anak belum bisa memahami arti kata dalam cerita, sehingga anak menjadi kurang memahami maksud cerita yang disampaikan oleh guru. Berdasarkan wawancara kepada ibu Sumaita selaku guru di kelompok B, beliau mengatakan bahwa anak sudah diajarkan tentang bagaimana mengenal keaksaraan dengan cara menggunakan metode demonstrasi. Namun dalam kesehariannya sebagian besar anak tidak mampu mempraktekkan dalam kegiatan pembelajaran. Menurut hasil wawancara dengan kepala sekolah TK yang ada di Wonorejo penggunaan metode bercerita atau mendongeng bertujuan hanya untuk meningkatkan keterampilan berbicara anak dan meningkatkan daya ingat pada anak, tidak bertujuan sebagai pengenalan kemampuan keaksaraan. Dengan demikian metode bercerita atau mendongeng dianggap kurang berpengaruh terhadap kemampuan keaksaraan anak usia dini. Berdasarkan hasil observasi dan wawancara tersebut dapat disimpulkan bahwa anak kurang memahami pengetahuan keaksaraan meskipun sudah diajarkan. Melihat kondisi tersebut maka pembelajaran mengenai keaksaraan perlu dimaksimalkan menggunakan media pembelajaran yang ada sesuai dengan karakteristik anak yaitu dengan menggunakan media pembelajaran dongeng fabel.

Berdasarkan uraian latar belakang
diatas mengenai kemampuan keaksaraan pada anak usia dini dan media pembelajaran, peneliti tertarik untuk meneliti tentang "Pengembangan Media Buku Dongeng Fabel Untuk Mengenalkan Kemampuan Keaksaraan Anak Usia 5-6 Tahun Di Wonorejo Glagah Lamongan”.

\section{METODE PENELITIAN}

Pengembangan buku dongeng fabel merupakan penelitian pengembangan atau Research and Development (R\&D) dalam bidang pendidikan. Penelitian pengembangan atau Research and Development (R\&D) diartikan sebagai metode penelitian yang digunakan untuk menghasilkan produk tertentu, dan menguji keefektifan produk tersebut (Sugiyono, 2014). Pengembangan ini difokuskan untuk mengembangkan media pembelajaran berupa buku dongeng fabel. Produk akhir dari penelitian ini diharapkan dapat membantu guru dalam proses pembelajaran menjadi lebih aktif, efektif dan menarik, khususnya di Wonorejo Glagah Lamongan. Media pembelajaran buku dongeng fabel yang dikembangkan adalah untuk mengenalkan kemampuan keaksaraan anak usia dini.

Metode penelitian dan pengembangan ini menggunakan model pengembangan ADDIE. Model pengembangan ADDIE dikembangkan oleh Reisser dan Mollenda untuk merancang sistem pembelajaran. ADDIE merupakan singkatan dari Analysis (Analisis), Design (Desain), Development (Pengembangan), Implementation (Implementasi), Evaluation (Evaluasi) (Mulyatiningsih, 2011). Dalam model pengembangan ADDIE memudahkan pengembang dalam mengembangkan media buku dongeng fabel.

Subjek uji coba yang digunakan dalam penelitian ini adalah validasi ahli (ahli materi dan bahasa, ahli media pembelajaran) dan anak usia 5-6 tahun di Wonorejo Kecmatan Glagah Kabupaten Lamongan. Pemilihan validasi ahli sesuai dengan bidang yang 
Jurnal PG-PAUD Trunojoyo : Jurnal Pendidikan dan Pembelajaran Anak Usia Dini, Volume 7, Nomor 2, Oktober 2020 hal 62-68, ISSN : 2528-3553 (online), ISSN: 2407-4454 (print)

terkait dengan penelitian. Penelitian ini menggunakan jenis data kuantitatif dan kualitatif. Hal ini digunakan untuk mendapatkan penilaian dari hasil angket dan saran perbaikan yang diberikan oleh subjek uji coba.

Instrumen pengumpulan data dalam penelitian ini yaitu angket dan dokumentasi. Angket berfungsi untuk pengambilan penilaian dari validasi ahli dan respon anak terhadap media buku dongeng fabel yang sudah dikembangkan, sedangkan dokumentasi digunakan untuk pengambilan bukti foto dalam pengambilan data.

Teknik analisis data yang digunakan adalah analisis kuantitatif dan deskripsi kualitatif. Data penelitian pengembangan yang dianalisis menggunakan analisis kuantitatif adalah analisis kelayakan yang mana validasi yang dilakukan untuk mengetahui kelayakan media buku dongeng fabel yaitu dengan cara melakukan analisis dari validasi ahli materi dan ahli media atau angket yang terkumpul. Data diperoleh merupakan data kuantitatif, dari hasil yang diperoleh dapat dihitung presentasenya menggunakan rumus berikut (Akbar, 2013).

$$
V a=\frac{\text { Tse }(\text { skor yang diperoleh })}{\text { Tsh }(\text { skor maksimal })} \times 100 \%
$$

Keterangan:

$\mathrm{Va}=$ Skor Validasi

Tse = Skor yang diperoleh

Tsh $=$ Skor maksimal

\section{Tabel 1. Kriteria Skala Likert}

\begin{tabular}{|c|lcc|l|}
\hline $\begin{array}{c}\text { No } \\
.\end{array}$ & \multicolumn{2}{|c|}{ Kriteria } & \multicolumn{2}{c|}{$\begin{array}{c}\text { Tingkat } \\
\text { Validitas }\end{array}$} \\
\hline 1. & $\begin{array}{l}\text { Skor } \\
100 \%)\end{array}$ & $(90 \%-$ & $\begin{array}{l}\text { Sangat sesuai, } \\
\text { sangat layak, } \\
\text { sangat valid }\end{array}$ \\
\hline 2. & $\begin{array}{l}\text { Skor } \\
89 \%)\end{array}$ & 4 & $(75 \%-$ & $\begin{array}{l}\text { Sesuai, layak, } \\
\text { valid }\end{array}$ \\
\hline 3. & $\begin{array}{l}\text { Skor } \\
74 \%)\end{array}$ & 3 & $(65 \%-$ & $\begin{array}{l}\text { Cukup sesuai, } \\
\text { cukup layak, } \\
\text { cukup valid }\end{array}$ \\
\hline 4. & $\begin{array}{l}\text { Skor } \\
64 \%)\end{array}$ & 2 & $(55 \%-$ & $\begin{array}{l}\text { Tidak sesuai, } \\
\text { tidak layak, } \\
\text { tidak valid }\end{array}$ \\
\hline 5. & $\begin{array}{l}\text { Skor } \\
54 \%)\end{array}$ & 1 & $(0 \%-$ & $\begin{array}{l}\text { Sangat tidak } \\
\text { sesuai, sangat } \\
\text { tidak layak, } \\
\text { sangat tidak } \\
\text { valid }\end{array}$ \\
\hline
\end{tabular}

Pengambilan keputusan tentang kualitas produk media pembelajaran pada angket uji coba pengembang menggunakan skala likert (Sugiyono, 2014). Analisis kualitatif digunakan untuk mengolah data dari hasil data para ahli dan data uji coba pada anak usia 5-6 tahun di Wonorejo Kecamatan Glagah Kabupaten Lamongan. Teknik analisis kualitatif dilakukan dengan mengklasifikasikan informasi berupa tanggapan, kritik dan saran perbaikan yang terdapat pada angket yang sudah terisi angka penilaian. Informasi tersebut digunakan untuk perbaikan produk pengembangan media buku dongeng fabel. Hasil analisis kualitatif ini untuk mengumpulkan informasi saran perbaikan dari subjek uji coba.

\section{HASIL DAN PEMBAHASAN}

Hasil penelitian pengembangan media buku dongeng fabel terhadap kemampuan keaksaraan anak usia 5-6 tahun di Wonorejo Glagah Lamongan menjelaskan tentang kelayakan media buku dongeng fabel sebagai media pembelajaran. Penilaian dilihat dari 
Jurnal PG-PAUD Trunojoyo : Jurnal Pendidikan dan Pembelajaran Anak Usia Dini, Volume 7, Nomor 2, Oktober 2020 hal 62-68, ISSN : 2528-3553 (online), ISSN: 2407-4454 (print)

hasil bukti pada lembar angket yang diberikan kepada subjek uji coba. Berikut hasil penelitian dari uji coba ahli (materi dan bahasa, media pembelajaran) serta uji coba lapangan (perseorangan dan kelompok kecil).

Hasil presentase yang diperoleh dari angket ahli media pembelajaran terhadap produk media buku dongeng fabel yakni sebesar 66,6\%. Dilihat dari angket ahli media pembelajaran yang diperoleh disesuaikan dengan tabel 1 (Sugiyono, 2014) dapat dikatakan "Cukup Layak" digunakan dengan revisi. Hasil presentase yang diperoleh dari angket ahli materi dan bahasa terhadap produk media buku dongeng fabel yakni sebesar $84,5 \%$. Dilihat dari angket ahli materi dan bahasa yang diperoleh disesuaikan dengan tabel 1 (Sugiyono, 2014) dapat dikatakan "Layak" digunakan dengan revisi.

Hasil presentase yang diperoleh dari angket uji coba lapangan perseorangan terdiri dari 2 anak terhadap produk media buku dongeng fabel yakni sebesar 85,5\%. Dilihat dari angket uji coba lapangan perseorangan yang diperoleh disesuaikan dengan tabel 1 (Sugiyono, 2014) dapat dikatakan "Layak" digunakan. Hasil presentase yang diperoleh dari angket uji coba lapangan kelompok kecil terdiri dari 3 anak terhadap produk media buku dongeng fabel yakni sebesar 92,5\%. Dilihat dari angket uji coba lapangan kelompok kecil yang diperoleh disesuaikan dengan tabel 1 (Sugiyono, 2014) dapat dikatakan "Sangat Layak" untuk digunakan. Berdasarkan hasil analisis data tersebut, media buku dongeng fabel Elang dan Kelinci memiliki kualifikasi layak untuk digunakan dalam pembelajaran untuk mengenalkan kemampuan keaksaraan pada anak usia dini. Berikut adalah gambar media buku dongeng fabel Elang dan Kelinci.

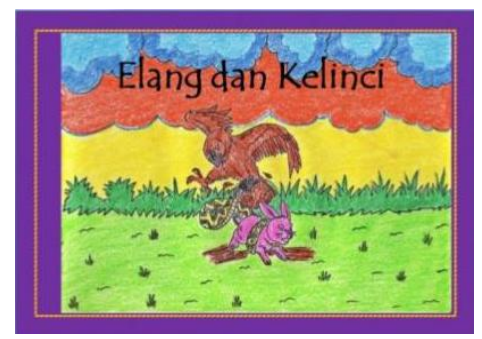

Gambar 1. Cover Buku Dongeng Fabel

\section{SIMPULAN DAN SARAN}

Produk yang dikembangkan dalam penelitian pengembangan ini adalah berupa media pembelajaran dongeng fabel Elang dan Kelinci untuk mengenalkan kemampuan keaksaraan anak usia dini. Penelitian pengembangan ini telah melalui uji coba produk sebanyak 4 tahapan yang meliputi, uji coba ahli media, uji coba materi dan bahasa, uji coba lapangan perseorangan, uji coba lapangan kelompok kecil. Penelitian pengembangan media buku dongeng fabel ini hanya sampai pada uji coba lapangan kelompok kecil dikarenakan dilakukan pada saat terjadinya pandemi Covid-19, sehingga tidak dapat melanjutkan uji coba lapangan kelompok besar karena adanya larangan pengumpulan massa.

Berdasarkan hasil analisis data pada pembahasan sebelumnya, uji coba ahli media pembelajaran memperoleh presentase 66,6\% dengan kategori "Cukup Layak", uji coba ahli materi dan bahasa memperoleh presentase 84,5\% dengan kategori "Layak". Untuk analisis dan uji coba lapangan perseorangan memperoleh presentase $85,5 \%$ dengan kategori "Layak", uji coba lapangan kelompok kecil memperoleh presentase 92,5\% dengan kategori "Sangat Layak". Berdasarkan hasil analisis data tersebut, media dongeng fabel Elang dan Kelinci memiliki kualifikasi layak untuk digunakan dalam pembelajaran untuk mengenalkan kemampuan keaksaraan pada anak usia dini.

Adapun saran dari penelitian ini adalah sebagai berikut:

1. Mengingat produk yang dikembangkan bermanfaat dalam pembelajaran, maka 
Jurnal PG-PAUD Trunojoyo : Jurnal Pendidikan dan Pembelajaran Anak Usia Dini, Volume 7, Nomor 2, Oktober 2020 hal 62-68, ISSN : 2528-3553 (online), ISSN: 2407-4454 (print)

disarankan guru untuk dapat menggunakan (mendongeng) dengan media ini.

2. Penggunaan produk media pembelajaran ini bisa digabungkan dengan media lainnya.

3. Menggunakan jenis dan ukuran serta jenis huruf yang paling sesuai dengan karakteristik anak usia dini.

4. Menggunakan bahasa yang tepat untuk anak usia dini.

5. Untuk tindak lanjut pengembang, sebaiknya jika pengembang tidak hanya berhenti pada uji coba produk tetapi pada tahap produksi masal.

\section{DAFTAR PUSTAKA}

Aisyah, S dkk. (2012). Perkembangan dan Konsep Dasar Pengembangan Anak Usia Dini, Tangerang Selatan: Universitas Terbuka.

Akbar, S. (2013). Instrumen Perangkat Pembelajaran. Bandung: PT.Remaja Rosdakarya

Eliyawati, C. (2005). Pemilihan dan Pengembangan Sumber Belajar. Jakarta. Direktorat Pembinaan Pendidikan.

Fadlillah, M. (2012). Desain Pembelajaran $P A U D$, Jogjakarta: Ar-Ruzz Media.

Mukhtar, I. (2014). Desain Pembelajaran Berbasis TIK, Jakarta: Referensi.

Mulyatiningsih, E. (2011). Riset Terapan Bidang Pendidikan dan Teknik, Yogyakarta: UNY Press.

Mutiah, D. (2010). Psikologi Bermain Anak Usia Dini, Jakarta: Kencana.

Peraturan Menteri Pendidikan dan Kebudayaan Republik Indonesia Nomor 137 Tahun 2014 Tentang Standar Nasional Pendidikan Anak Usia Dini Standar Isi Tingkat Pencapaian Perkembangan Anak Lampiran 1.

Sugiyono. (2014). Metode Penelitian Pendidikan Pendekatan Kuantitatif,
Kualitatif, dan $R \& D, \quad$ Bandung: Alfabeta.

Yusro, S. (2013). Pembelajaran Keaksaraan Untuk Anak Usia Dini, Jurnal Pendidikan Anak. Yogyakarta. 